\title{
Flexible Sierpinski Carpet Fractal Antenna on a Hilbert Slot Patterned Ground
}

\author{
Vasa Radonić, ${ }^{1}$ Keith Palmer, ${ }^{2}$ Goran Stojanović, ${ }^{1}$ and Vesna Crnojević-Bengin ${ }^{1}$ \\ ${ }^{1}$ Faculty of Technical Sciences, University of Novi Sad, Trg Dositeja Obradovića 6, 21000 Novi Sad, Serbia \\ ${ }^{2}$ Department of Electrical and Electronic Engineering, Stellenbosch University, Private Bag X1, Matieland, \\ Stellenbosch 7602, South Africa \\ Correspondence should be addressed to Vasa Radonić, vasarad@uns.ac.rs \\ Received 15 December 2011; Accepted 5 April 2012 \\ Academic Editor: Carles Fernández-Prades
}

Copyright () 2012 Vasa Radonić et al. This is an open access article distributed under the Creative Commons Attribution License, which permits unrestricted use, distribution, and reproduction in any medium, provided the original work is properly cited.

This paper presents a novel design of fractal antenna on a flexible substrate that operates in UMTS band (universal mobile telecommunication system, 1.92-2.17 GHz). The antenna consists of a Sierpinski carpet fractal radiator, which reduces the overall size of the antenna, and it is realized on top of a Hilbert slot in the ground layer, to achieve required impedance matching. The antenna is compact with the overall dimensions equal to $70 \mathrm{~mm} \times 31 \mathrm{~mm} \times 0.075 \mathrm{~mm}$. Influence that folding has on the initial planar topology is investigated in detail. The obtained results show that the proposed antenna is more tolerant to folding than the conventional patch and that it exhibits relatively stable radiation patterns even when folded in complex manners.

\section{Introduction}

Designing a small antenna with good bandwidth performance presents a challenge for modern communication devices, such as Bluetooth or WLAN devices. To minimize the size of the antenna or to improve its characteristics, various solutions based on fractal geometry have recently been proposed [1-8]. Different fractal geometries, such as Peano, Hilbert, or Sierpinski curves, have been used to bring forth the benefits of small size $[2,4,6-8]$, wide bandwidth [5], or multiband operation $[3,5,6]$. This paper presents a fractal topology that is tolerant to folding.

Fractal curves are unique for their self-similarity and space-filling properties. Due to the self-similarity, a fractal antenna being made up of many differently scaled copies of itself is likely to maintain similar radiation parameters in different bands proportional to the wavelengths. On the other hand, the space-filling property of fractals allows theoretically the design of infinite-length lines on finite substrate areas, thus leading to compact antennas.

Flexible electronics are becoming more viable with the recent technological developments opening up possibilities to integrate wireless functions into clothing, moving objects, or into animals to monitor various parameters of interest.
Although flexible technology offers components that can bend together with the host medium (e.g., textile) with practically no disturbance to the subject wearing it, bending can significantly deteriorate the performances of the wireless components, most notably the antenna. Significant research efforts are currently focused on study and analyzing the viability of these flexible substrate materials. Several experimental studies have been carried out recently to investigate the effects of antenna bending on its characteristics such as resonant frequency, return loss, impedance bandwidth, gain, and radiation patterns [8-13].

In this paper, we propose a novel flexible antenna based on the Sierpinski carpet fractal curve of the third order, realized on a Hilbert slotted ground. The proposed antenna was simulated using CST Microwave Studio and compared with the conventional patch antenna. Impact of folding on both antennas was analyzed in details. To validate the simulation results, the proposed antenna was fabricated and measured.

\section{Fractal Antenna}

The proposed antenna consists of a Sierpinski carpet radiator realized on the top side of the flexible substrate with 


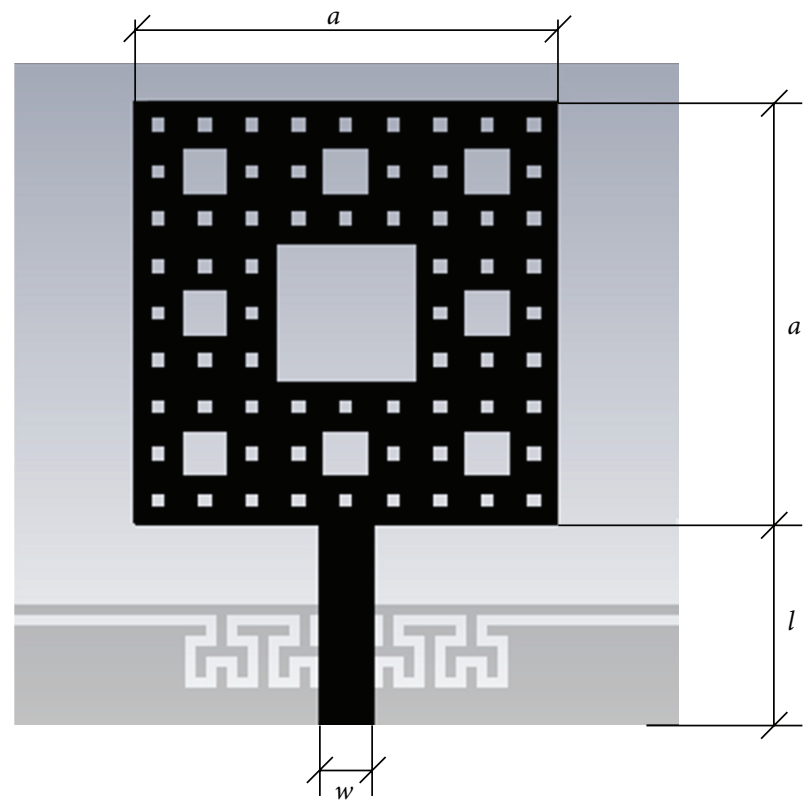

(a)

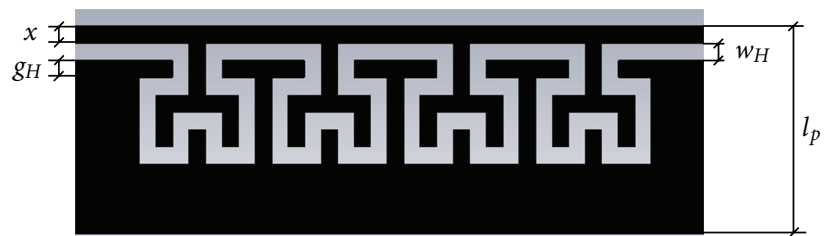

(b)

FIgURE 1: (a) Proposed fractal antenna on a Hilbert slot patterned ground (black: top metallic layer, dark gray: bottom metallic layer); (b) magnified detail of the patterned ground under the feed line (black: bottom metallic layer).

a Hilbert slot on the bottom side (Figure 1). The Sierpinski carpet antenna is in essence a square metallic patch divided into 9 congruent subsquares in a 3-by-3 grid, in which the metallization of the middle square section is removed. The same procedure is then applied recursively to the remaining 8 subsquares and again to the resulting elements. In that manner, the third-order fractal antenna is obtained with the dimensions of the radiator equal to $20 \mathrm{~mm} \times 20 \mathrm{~mm}$. The antenna is fed by a $2.6 \mathrm{~mm}$ wide and $10 \mathrm{~mm}$ long microstrip line.

In order to match the antenna to a $50 \Omega$ SMA connector, four serially connected slots in the shape of the Hilbert fractal curve of the second order were printed in the ground plane (Figure 1(b)). The position and line width and spacing of the Hilbert slot are the most important parameters for the impedance matching as well as for obtaining a good radiation pattern and reflection coefficient of the antenna. The position $x$ and the line width and spacing, denoted $w_{H}$ and $g_{H}$, respectively, were optimized with the following values obtained: $x=0.6 \mathrm{~mm}, w_{H}=g_{H}=0.5 \mathrm{~mm}$. The total length of the Hilbert slot is $6 \mathrm{~mm}$. As can be seen from Figure 1(b), there is no ground plane under the radiator. The existing ground plane is split into two sections by the Hilbert slot, generating some electromagnetic coupling. As a consequence, apart from the reduction of the ground plane area, a decrease of the antenna resonant frequency is obtained, which additionally contributes to antenna miniaturization.

The antenna was designed using a $0.075 \mathrm{~mm}$ thick Kapton substrate with relative permittivity $\varepsilon_{r}=3.2$ and dissipation factor equal to 0.0019 . All simulations were performed using CST Microwave Studio.
Various ways of bending the antenna were analyzed, shown in Figure 2. In Figure 2(a) the antenna is folded along one-third of its length in the $y$-direction, and two-thirds in Figure 1(b). In the cases shown in Figures 1(c) and 1(d) more demanding modifications are made: the antenna was folded twice, along the one and two third of its length, resulting in structures with a cross-section similar to letters $\mathrm{C}$ and $Z$, respectively. In that way, the dimensions of the antenna were significantly changed: its length was decreased while its height was increased.

Figure 3 compares the simulated return loss of the initial planar fractal antenna with the return losses of its folded modifications. More detailed results are presented in Table 1, where the proposed fractal antenna is also compared to the conventional patch antenna realized on a partial ground plane and tuned to the same frequency, as well as to the patch's folded modifications obtained by bending the patch antenna in the same manner as shown in Figure 2. Final dimensions of the patch radiator are $24 \mathrm{~mm} \times$ $24 \mathrm{~mm}$, while the length of the partial ground is $2.1 \mathrm{~mm}$. To facilitate the comparison, frequency shifts and variations in the bandwidth are also listed in Table 1, relative to the planar versions of the antenna in question.

As expected, it can be seen that any folding of the antenna directly impacts on its performances. However, this impact is significantly reduced in the case of the proposed fractal antenna: the frequency shift of the patch antenna due to bending ranges between 2.42 and $6.81 \%$, while it is equal to $3.4 \%$ for the worst-case fractal antenna. Fractional bandwidth of the fractal antenna changes up to $25.14 \%$, while conventional one exhibits $34.49 \%$. The average frequency shift for the patch antenna is $4.09 \%$ while 
TABLE 1: Detailed comparison between performances of the proposed fractal and the conventional patch antenna, for both the planar and the folded cases.

\begin{tabular}{|c|c|c|c|c|c|c|}
\hline Antenna type & Modification & $f_{r}[\mathrm{GHz}]$ & $\Delta f_{r}[\%]$ & FBW [\%] & $\Delta$ FBW $[\%]$ & $\mathrm{S}_{11}[\mathrm{~dB}]$ \\
\hline \multirow{5}{*}{ Fractal } & Planar & 1.9850 & - & 5.37 & - & -25.7 \\
\hline & 1 & 2.0120 & 1.36 & 4.02 & -25.14 & -14.7 \\
\hline & 2 & 2.0120 & 1.36 & 5.13 & -4.47 & -20.8 \\
\hline & 3 & 2.0525 & 3.40 & $\mathrm{n} / \mathrm{a}$ & $\mathrm{n} / \mathrm{a}$ & -9.4 \\
\hline & 4 & 2.0255 & 2.04 & 4.42 & -17.69 & -16.3 \\
\hline \multirow{5}{*}{ Patch } & Planar & 1.9445 & - & 9.8 & - & -34.4 \\
\hline & 1 & 1.9985 & 2.78 & 8.1 & -17.35 & -18.4 \\
\hline & 2 & 1.9915 & 2.42 & 8.35 & -14.80 & -22.5 \\
\hline & 3 & 2.0770 & 6.81 & 6.42 & -34.49 & -23.6 \\
\hline & 4 & 2.0295 & 4.37 & 7.83 & -20.10 & -33.5 \\
\hline
\end{tabular}

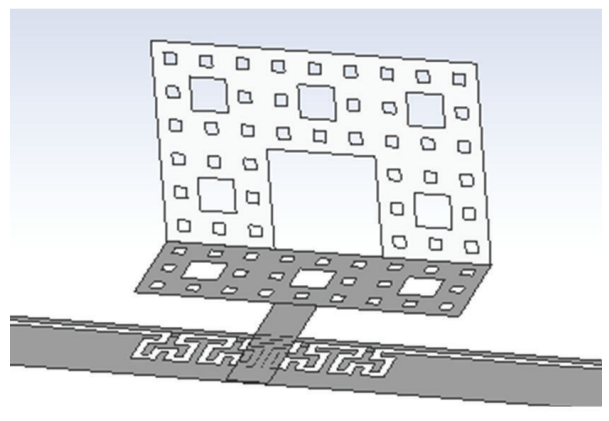

(a)

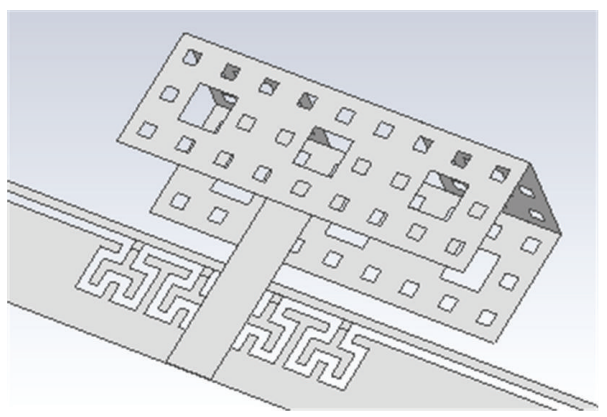

(c)

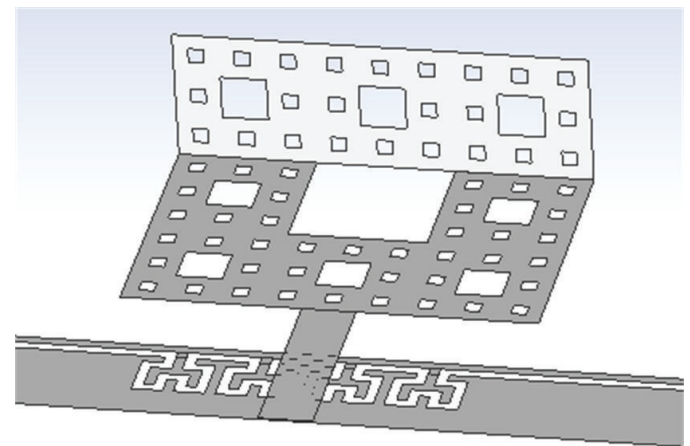

(b)

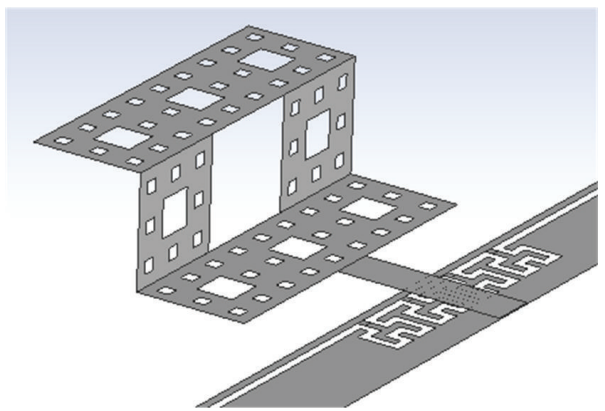

(d)

FIgURE 2: Different ways of folding the antenna: (a) modification 1, (b) modification 2, (c) modification 3, and (d) modification 4.

it is only $2.04 \%$ for the proposed fractal antenna. The same holds for the average variation of the fractional bandwidth: $21.7 \%$ for the conventional antenna versus only $15.3 \%$ for the fractal antenna. Inspecting the tabulated results, it can be concluded that the deterioration of performance observed for simple modifications of the patch antenna (modifications 1 and 2) is similar to the case of complex modifications of the fractal antenna (modifications 3 and 4). This illustrates the robustness to folding that the proposed fractal antenna exhibits over the conventional patch. In the same time, the fractal antenna occupies $30 \%$ smaller substrate area than the patch, and it is less sensitive to mechanical strain.

In Figures 4 and 5 radiation patterns in E-plane and $\mathrm{H}$ plane for the planar fractal and patch antennas and their modifications relative to the flat antennas are shown. The patterns are omnidirectional in $\mathrm{H}$-plane. The average gain reduction in the case of conventional antenna is $46 \%$, while the fractal antenna exhibits $41 \%$. It can be seen that the change of the main lobe directivity is similar for both antennas and equal to $40 \%$.

\section{Fabrication and Measurement}

The proposed fractal antenna was fabricated using a Dimatix [14] material deposition printer DMP-3000, which is cartridge-based piezo inkjet printing system which enables direct deposition of fluids (functional materials). The resolution of the inkjet process is mainly governed by the nozzle diameter (approximately the droplet diameter) and the statistical variation of the droplet flight and spreading on the substrate. Resolution can be modified by adjusting 


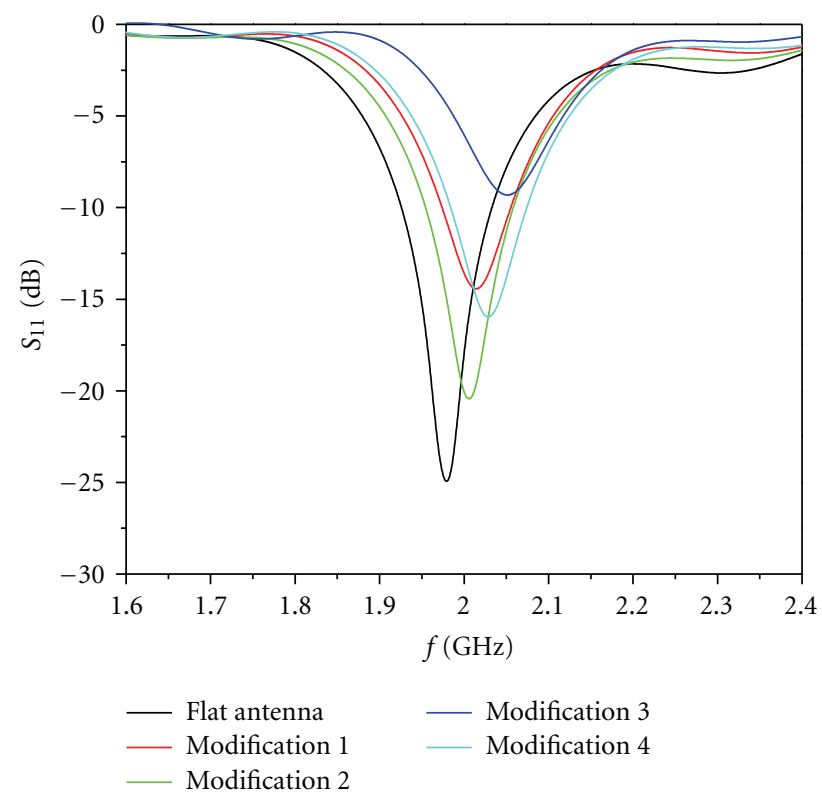

FiguRE 3: Simulated return loss for the proposed planar fractal antenna and its folded modifications.

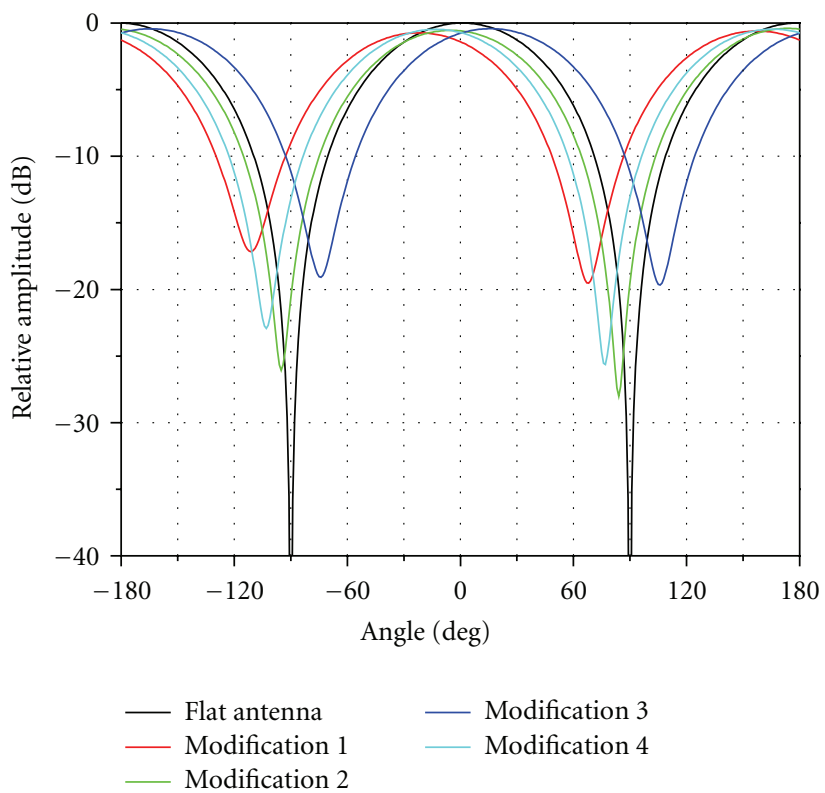

(a)

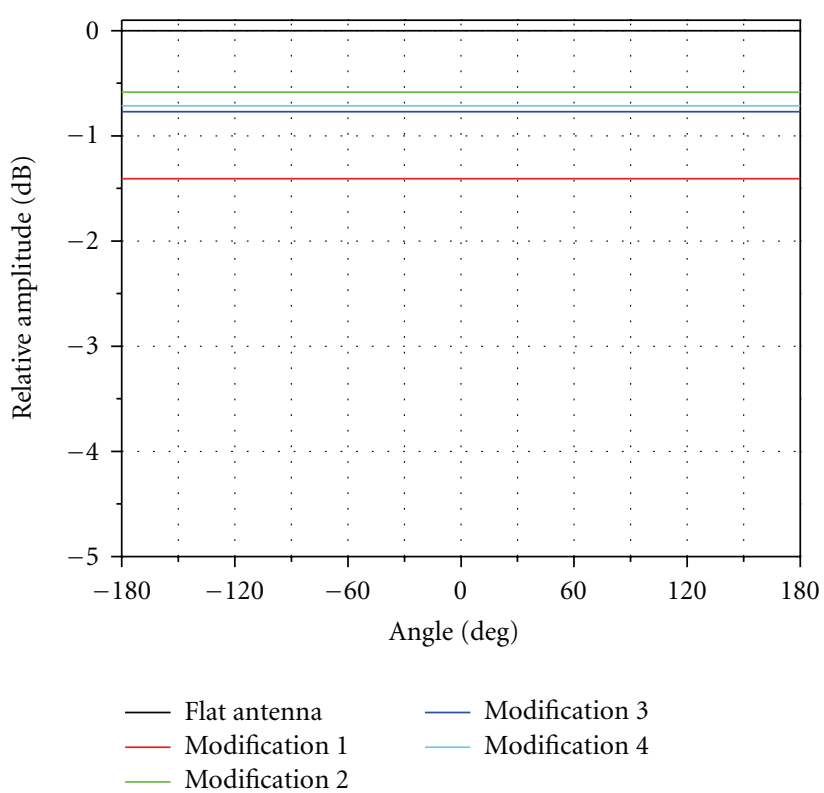

(b)

FIGURE 4: Radiations patterns for the proposed fractal antenna: (a) radiation pattern in E-plane, (b) radiation pattern in H-plane.

the angle of the printhead during printing. In the case of printing with silver nanoparticle ink (Suntronic Jet Silver U6503, [15]), the minimum droplet diameter was around $50 \mu \mathrm{m}$ and drop spacing was $25 \mu \mathrm{m}$ (center to center) which has obtained by changing the printhead angle. 16 nozzle printhead with the capacity of $1.5 \mathrm{~mL}$ was used. Spacing between each nozzle is 254 microns; nozzle diameter is around $25 \mu \mathrm{m}$ with average drop sizes of $10 \mathrm{pl}$. The voltage waveform amplitude used for piezoelement actuation was $27 \mathrm{~V}$, with a firing frequency of $4 \mathrm{kHz}$. The proposed antenna was printed on $75 \mu \mathrm{m}$ thick Kapton film substrate with dielectric constant of 3.2 and dissipation factor of 0.0019 [16]. After printing the pattern, silver nanoparticles were sintered on at $200^{\circ} \mathrm{C}$ for 45 minutes in order to get a uniform conductive structure of the fabricated antenna and the SMA connector was mounted using silver paste. Photographs of the fabricated fractal antennas are shown in Figure 6, while Figure 7 shows comparison of simulated and measured return loss for the planar fractal antenna and its measured gain.

Good agreement is observed, and the fundamental resonance occurs at $1.990 \mathrm{GHz}$ as predicted, with reflection better 


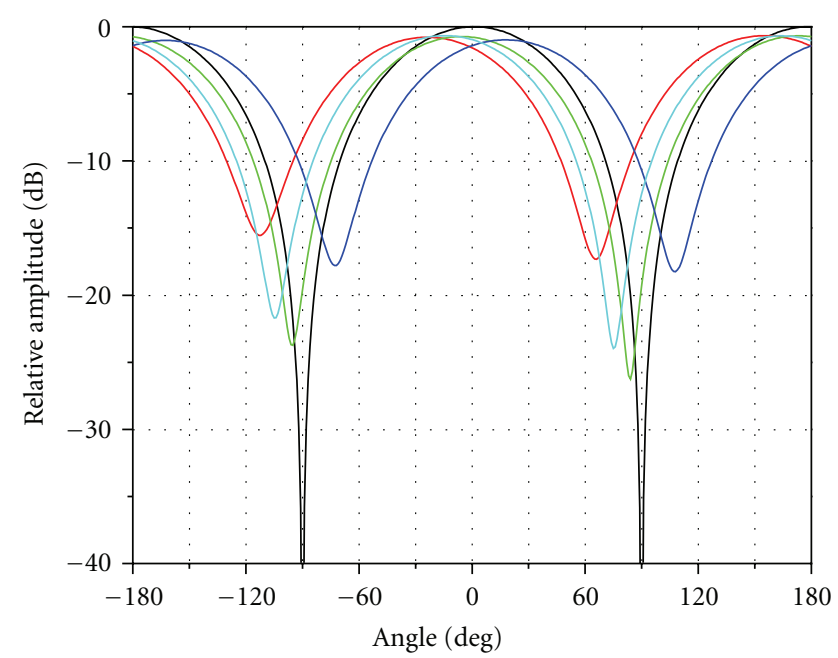

$\begin{array}{ll}\text { - Flat antenna } & \text { Modification 3 } \\ \text { Modification 1 } & \text { Modification 4 }\end{array}$

(a)

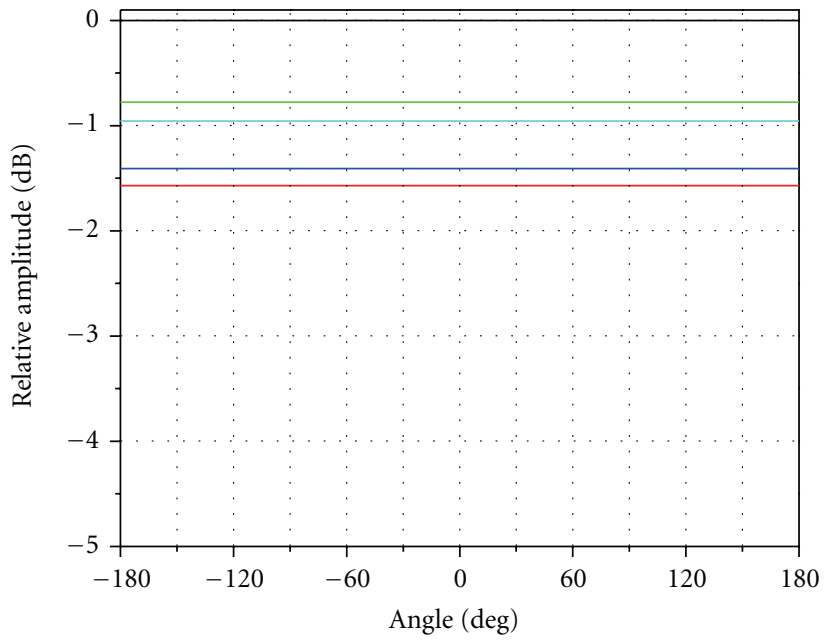

$\begin{array}{ll}\text { - Flat antenna } & \text { Modification } 3 \\ \text { - Modification } 1 & \text { Modification } 4\end{array}$

(b)

FIGURE 5: Radiations patterns for the conventional patch antenna: (a) radiation pattern in E-plane, (b) radiation pattern in H-plane.

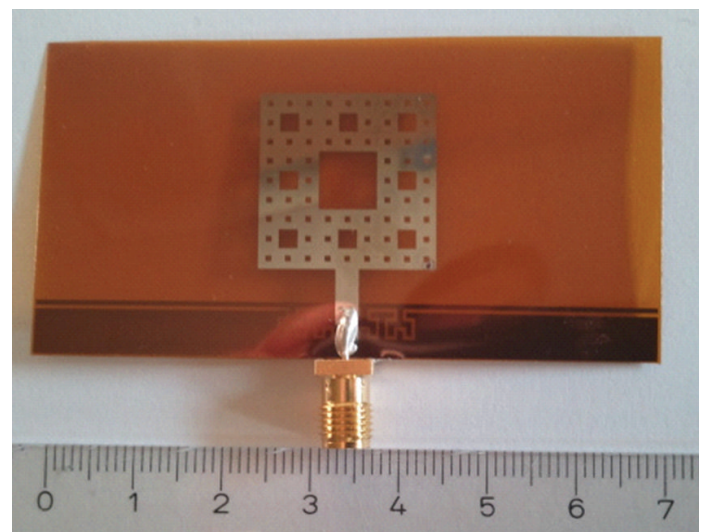

(a)

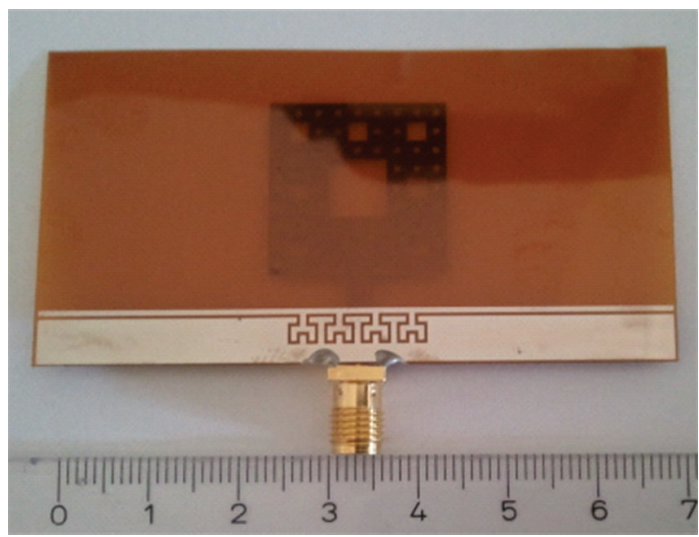

(b)

Figure 6: Photographs of the fabricated fractal antenna: (a) top layer, (b) bottom layer.

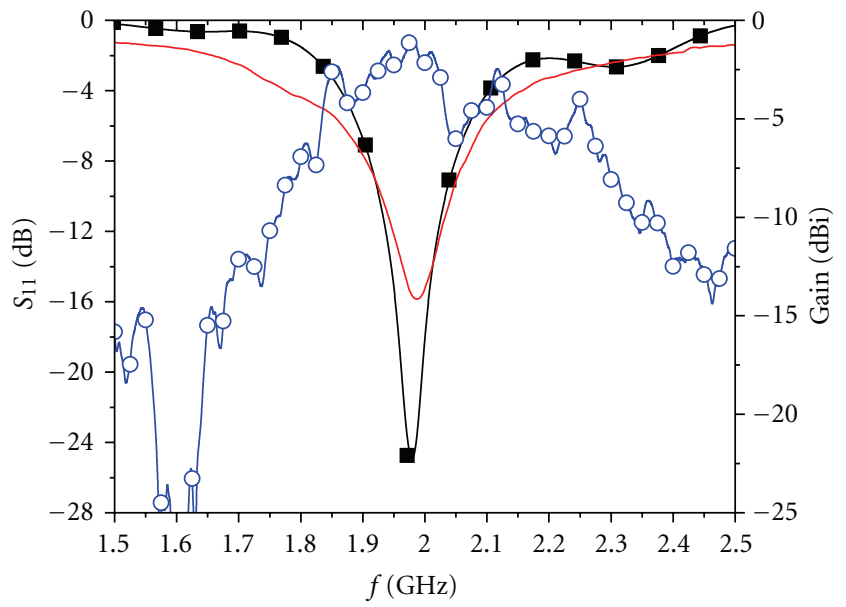

$\rightarrow$ Simulated $S_{11}$
- Measured $S_{11}$
-0 Measured gain

FIGURE 7: Comparison of simulated and measured return losses for the planar fractal antenna and the measured gain. 

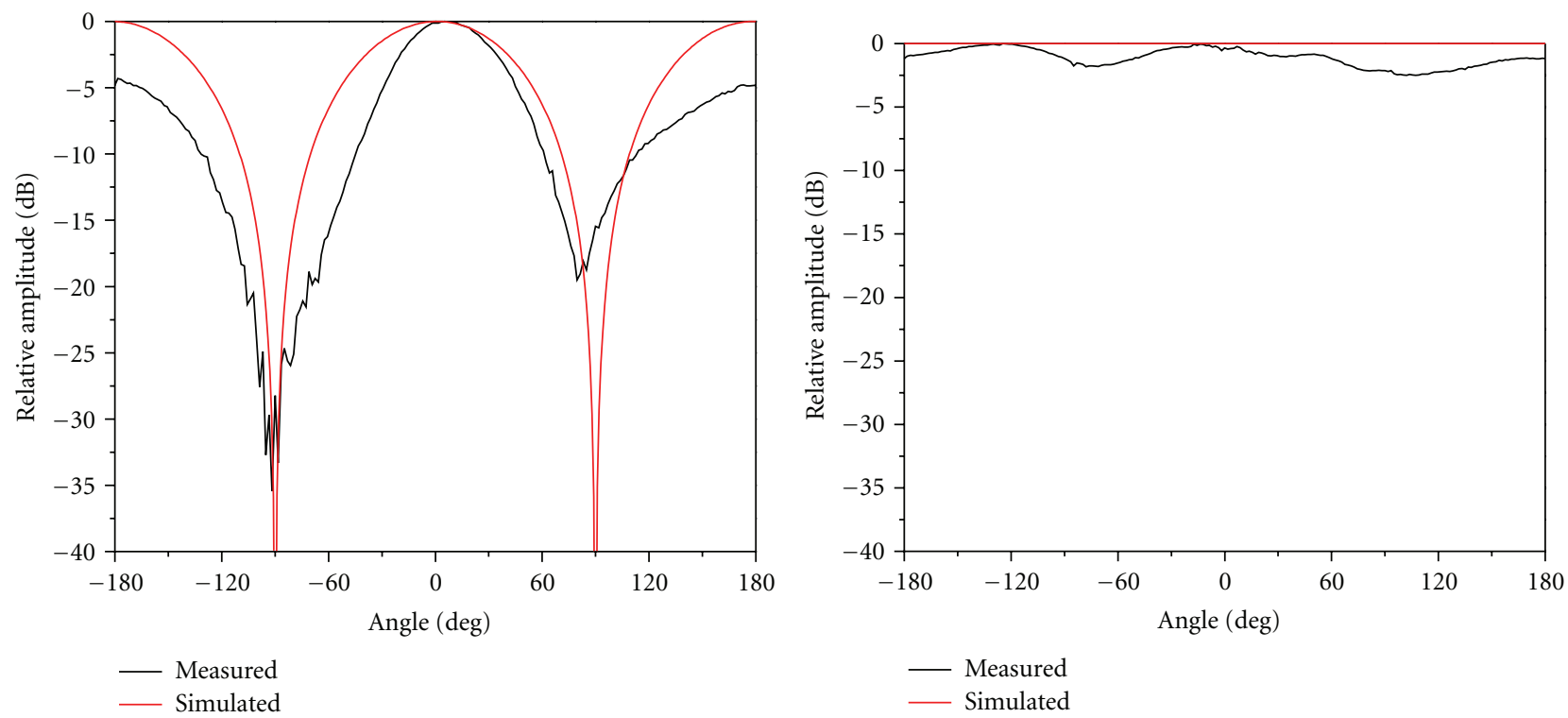

(a)
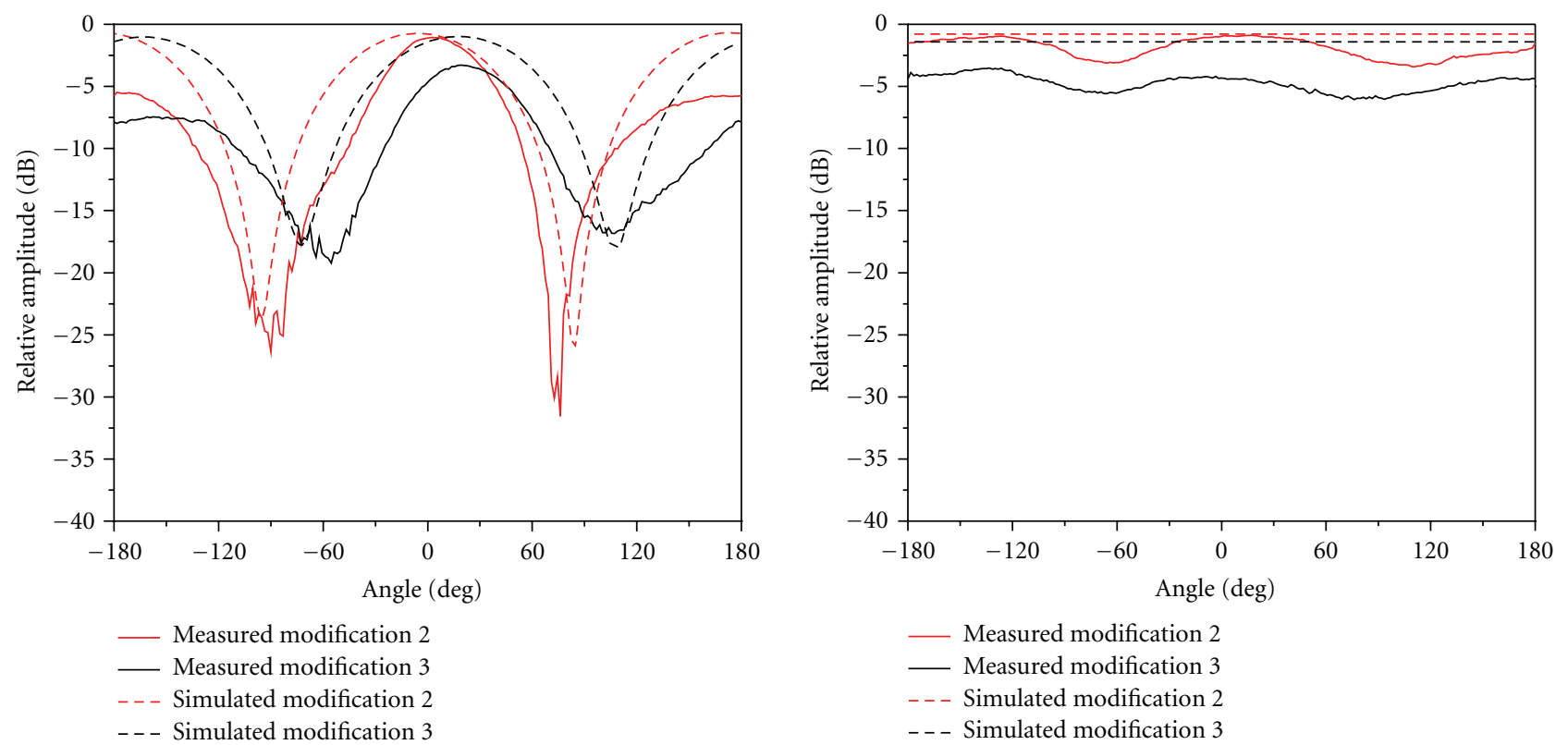

(b)

Figure 8: Comparison of simulated and measured radiations patterns in E-plane and H-plane for: (a) the planar fractal antenna and (b) modification 2 and modification 3 of the fractal antenna.

than $-15 \mathrm{~dB}$. The $-10 \mathrm{~dB}$ bandwidth is contained between $1.93 \mathrm{GHz}$ and $2.043 \mathrm{GHz}$, yielding $113 \mathrm{MHz}$ bandwidth, that is, $5.7 \%$.

Figure 8 shows the comparison of simulated and measured radiation patterns for the planar fractal antenna and its two modifications: modification 2 and modification 3 . The pattern measurements were taken in an anechoic chamber using a vector network analyzer, and the measured patterns agree well with the simulated ones bar for some ripple that is ascribed to reflections in the chamber.

\section{Conclusion}

A flexible Sierpinski carpet fractal antenna has been presented, more tolerant to folding than its conventional patch counterpart. The proposed antenna achieves improved performance such as the smaller influence of folding to the resonant frequency and the smaller variation of the gain, while the main lobe directivity changes similarly for both the fractal and the conventional antennas. The average frequency shift induced by folding of the patch antenna is $4.09 \%$ while it is only $2.04 \%$ for the proposed fractal antenna. The same 
holds for the average variation of the fractional bandwidth: $21.7 \%$ for the conventional antenna versus only $15.3 \%$ for the fractal antenna. Moreover, the proposed fractal antenna occupies $30 \%$ smaller surface than the patch, and it is less sensitive to mechanical strain.

\section{Acknowledgments}

This work has been partially supported by the European Commission through FP7 Project MultiWaveS, Grant no. PIRSES-GA-2009-247532. The authors thank the Department of Broadband Infocommunications and Electromagnetic Theory, Budapest University of Technology and Economics, Budapest, Hungary, for the anechoic chamber measurements.

\section{References}

[1] M. F. Pantoja, F. G. Ruiz, A. R. Bretones, and R. G. Martín, "GA design of wire pre-fractal antennas and comparison with other euclidean geometries," IEEE Antennas and Wireless Propagation Letters, vol. 2, pp. 238-241, 2003.

[2] I. K. Kim, J. G. Yook, and H. K. Park, "Fractal-shape small size microstrip patch antenna," Microwave and Optical Technology Letters, vol. 34, no. 1, pp. 15-17, 2002.

[3] C. Puente-Baliarda, J. Romeu, R. Pous, and A. Cardama, "On the behavior of the sierpinski multiband fractal antenna," IEEE Transactions on Antennas and Propagation, vol. 46, no. 4, pp. 517-524, 1998.

[4] J. Anguera, C. Puente, C. Borja, and J. Soler, "Fractal-shaped antennas: a review," in Wiley Encyclopedia of RF and Microwave Engineering, K. Chang, Ed., vol. 2, pp. 1620-1635, Wiley, New York, NY, USA, 2005.

[5] S. Wong and B. L. Ooi, "Analysus and bandwidth enchcement of Sierpinski carpet antenna," Microwave and Optical Technology Letters, vol. 31, no. 1, 2001.

[6] R. Azaro, E. Zeni, T. Gazzini, R. Dallapiccola, and A. Massa, "Synthesis of a three-dimensional triband (L1-L2 GPS and WiFi) prefractal tree antenna," Microwave and Optical Technology Letters, vol. 49, no. 9, pp. 2114-2118, 2007.

[7] J. P. Gianvittorio and Y. Rahmat-Samii, "Fractal antennas: a novel antenna miniaturization technique, and applications," IEEE Antennas and Propagation Magazine, vol. 44, no. 1, pp. 20-36, 2002.

[8] S. R. Best, "On the resonant properties of the Koch fractal and other wire monopole antennas," IEEE Antennas and Wireless Propagation Letters, vol. 1, pp. 74-76, 2002.

[9] E. C. Lee, P. J. Soh, N. B. M. Hashim et al., "Design and fabrication of a flexible Minkowski fractal antenna for VHF applications," in Proceedings of the 5th European Conference on Antennas and Propagation (EUCAP '11), pp. 521-524, April 2011.

[10] J. Jung, H. Lee, and Y. Lim, "Broadband flexible meander line antenna with vertical lines," Microwave and Optical Technology Letters, vol. 49, no. 8, pp. 1984-1987, 2007.

[11] S. Subramaniam and B. Gupta, "Design and development of flexible fabric antenna for body-worn applications and its performance study under flat and bent positions," Microwave and Optical Technology Letters, vol. 53, no. 9, pp. 2004-2011, 2011.

[12] T. F. Kennedy, P. W. Fink, A. W. Chu, N. J. Champagne, G. Y. Lin, and M. A. Khayat, "Body-worn E-textile antennas: the good, the low-mass, and the conformal," IEEE Transactions on Antennas and Propagation, vol. 57, no. 4, pp. 910-918, 2009.

[13] C. Hertleer, H. Rogier, L. Vallozzi, and L. Van Langenhove, "A textile antenna for off-body communication integrated into protective clothing for firefighters," IEEE Transactions on Antennas and Propagation, vol. 57, no. 4, pp. 919-925, 2009.

[14] http://www.dimatix.com/.

[15] http://www.sunchemical.com/.

[16] http://www.gts-flexible.co.uk. 

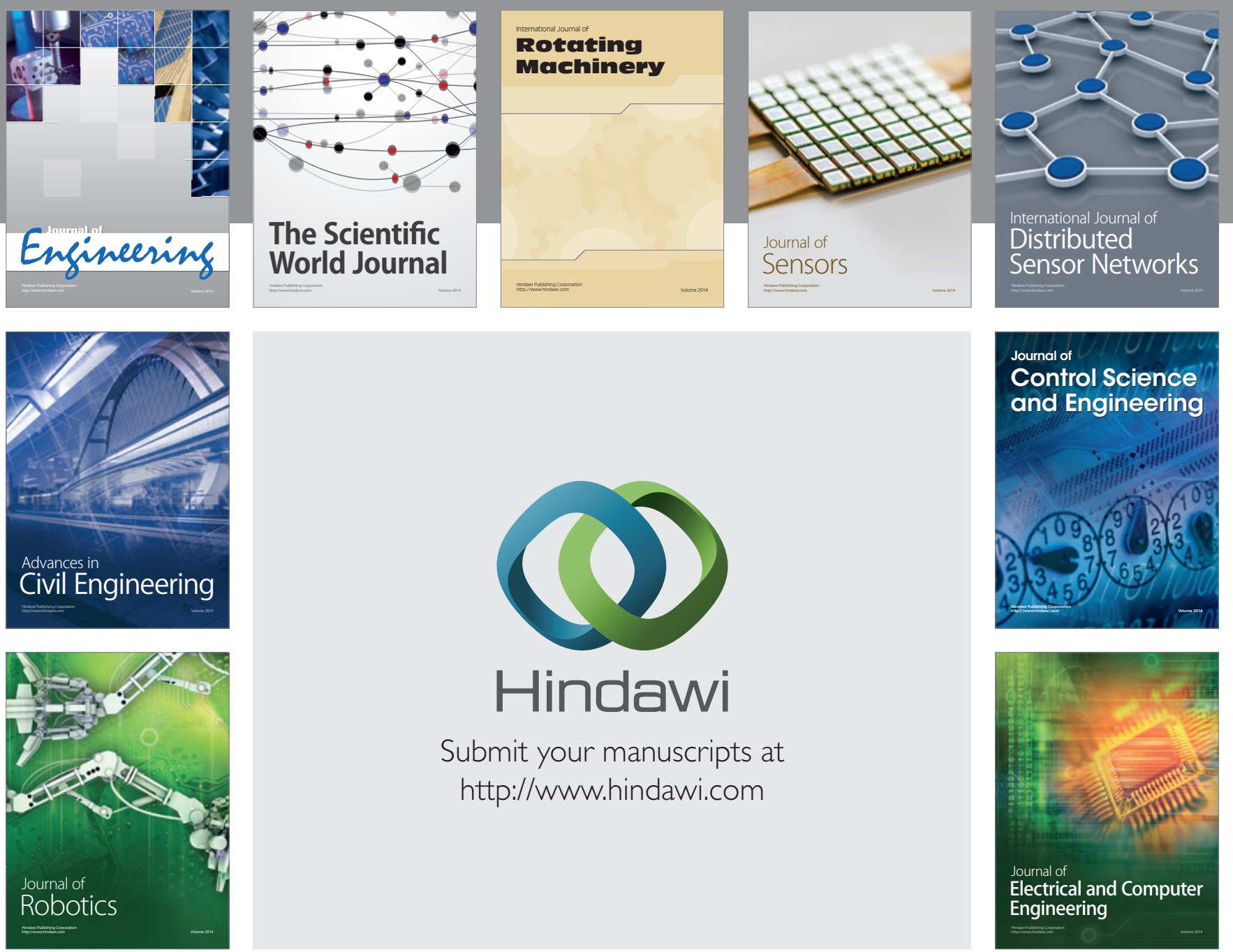

Submit your manuscripts at

http://www.hindawi.com
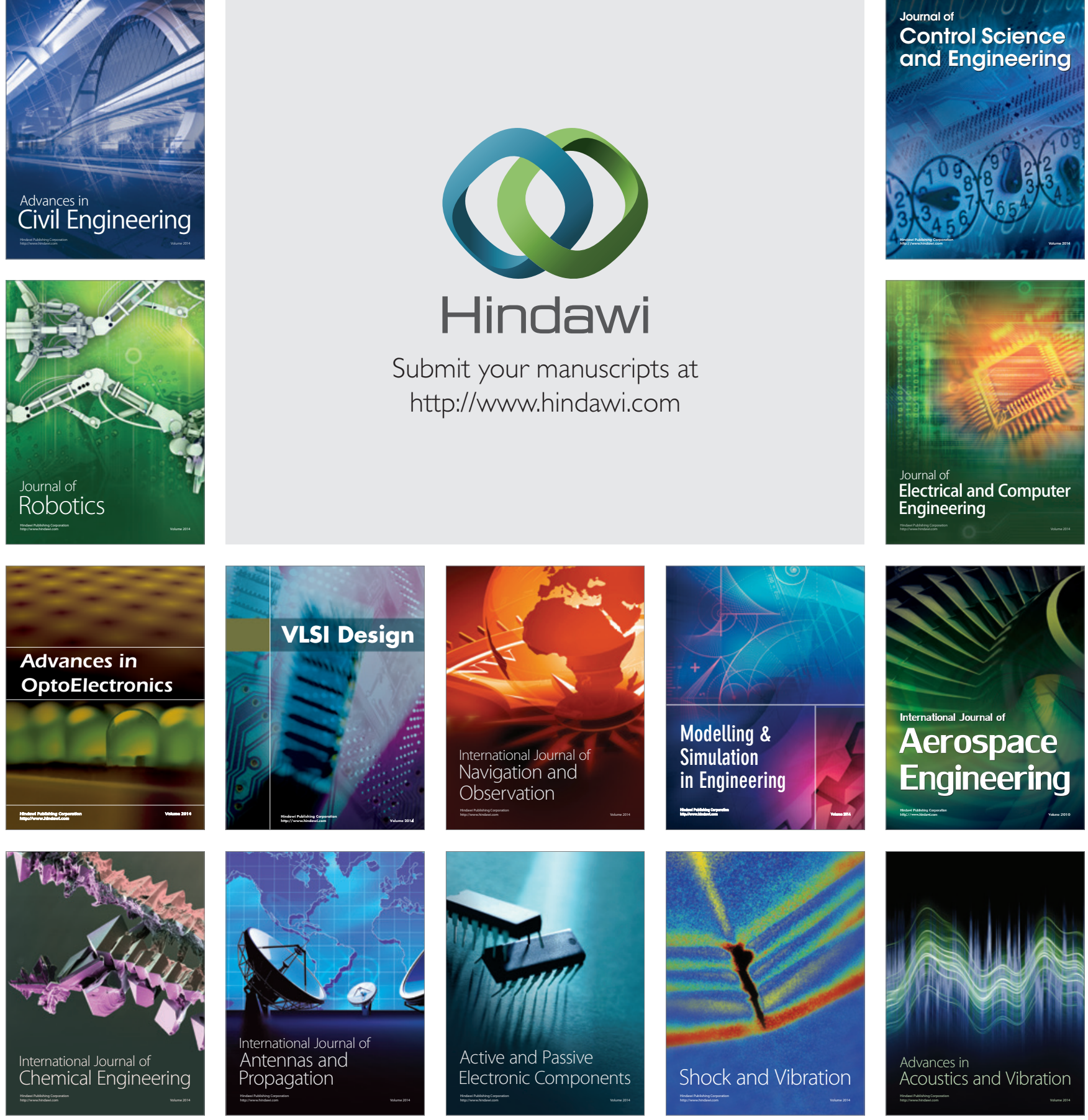